\title{
A Study of Mobile Apps in the Banking Industry
}

\author{
Radwan Ali, Mike Gallivan, Seema Sangari \\ Kennesaw State University \\ USA
}

\begin{abstract}
The purpose of this paper was to investigate the ratings of mobile apps in the banking industry for the sake of mobile development practices. We consulted a list of the top 50 riches banks registered with the U.S. Federal Deposit Insurance Corp. (FDIC). We collected ratings of the sample's mobile apps int the iTune Store in 2012, 2016, and 2018. Linear regression with Generalized Estimating Equations $(G E E)$ was used in data analysis. The findings from this study can help banks visit their mobile app development practices to understand user needs. Furthermore, managers can use the findings to assess their mobile app development strategies. This can help banks save effort, time, and money in their development projects.
\end{abstract}

\section{Introduction}

IS researchers and their counterparts in other fields, including computer science, cultural studies, and sociology have been conducting research on mobile business, services, and apps. This study identified over 45 papers in the leading IS journals in the past decade - in addition to special themed issues on mobile uses of IT [45], [65] or ratings of this domain [54]. Research has found that adopters of mobile technologies appreciate the access, convenience, and ease of use [27]. As information systems afford opportunities for more efficient business process and better performance, many businesses invest in information technologies while others are more cautious [64]. Mobile banking denotes access to banking information via an application (app) on a mobile device such as a smart phone or a tablet, as well as notifications via text messaging/short message service (SMS).

Banking has been evolving in response to the mass demand for cell phone access [9], or as widely known, mobile banking. Many firms started to look for new ways to leverage mobile devices into their business practices [56]. In May 2012, the iTunes Store listed 1,809 iPhone apps for banking institutions.

Mobile technologies have become commonplace for many types of business. Ngai and Gunasekaran [49] observed that "...from the 1990s onwards, we have been witnessing a great shift in methods of doing business with the emergence of electronic commerce... Mobile commerce (m-commerce) can be viewed as a subset of e-commerce...” (p. 3).

More than two dozen studies of m-banking have appeared in the last 12 years, with the vast majority of such studies examining the user acceptance and adoption issues [18]. Examples of studies from the individual adopter perspective include [47], [66], n (2006), [26], and [30]. A much smaller set of studies have taken the perspective of the banks themselves as they implement e-business and $\mathrm{m}$-business strategies [57], as studies identifying critical success factors (CSFs) of mobile banking from the banks' perspective [55]. The opportunities and challenges of $m$-business (mobile Internet as used in business) have taken center stage in IS research in recent years. This study inspected user ratings of banking mobile apps to assess the evolvement of such apps 10 years after the introduction of the iPhone by Apple.

\section{Rationale behind the Study}

There is much research on Internet banking that discusses various aspects such as investments in information technology (IT) [59], adoption [8], [36], [41], [60], success factors [55], and usability [18]. Most of the current research on mobile apps captures the consumer's perspective. The next few pages includes a large number of studies that emphasize that aspect.

Little literature is found to investigate mobile apps and their influence from the providing organization's side. Mobile apps have become a major player in creating value for business organizations [4], [62]. Not only are mobile apps helpful as tools for shopping for retailers, they can be promotional tools. This study starts the discussion on that important matter by investigating the mobile app ratings as indicators of development from the business' perspective and its influence on organizational performance.

\section{Literature Review}

This section is a summary of the literature of mobile app and mobile banking. It shows the tight relationship between the two constructs. The reader will notice that the literature focuses on the user ratings and reviews but lacks any examination of the bank's perspective.

Mobile app users typically access their mobile apps by visiting the "app store" of their phone's vendor (e.g., Apple, Google, Samsung, etc.). In addition to providing the ability to download specific mobile apps, such app stores provide useful descriptive information about the various apps, as 
well as numeric ratings from users, and often, qualitative reviews. Khalid, Shihab, and Nagappan 26] describe that the App Store affords users to assess apps by using star ratings and writing comments. Ratings data (numeric) and reviews (qualitative data) provide a rich source for much research on mobile apps. The star ratings are calculated on an app-level and version-level. The stars (ratings) and the comments (reviews) relay user perceptions about their respective apps. These ratings and reviews are helpful to app developers because they guide their product development. Mobile apps' characteristics of portability, personal nature, networkability, textual/visual content and convergence of multiple technologies (phone, search, entertainment, etc.) made them popular [29].

Lee and Raghu [30] explored success determinants of mobile apps. They used data from 300 charts in the App Store to find that high initial ranking, continuous quality updates, high use volume, and high user ranking scores are key factors. They considered that the variety of mobile apps would influence increase in competition because of their offerings (example, using a scan bar code reader app for price comparison).

Apple's iTune store has a top 100 lists for its free and paid apps. Taylor and Levin [62] found out that using a retail app was positively related to purchasing intentions. They concluded that Apple iOS users were increasingly open to retail mobile app usage, and consequently, product purchase. Their findings suggested that creating mobile apps are good investments (free or paid) for organizations because mobile app use can trigger brand loyalty.

This literature review section shared a large number of studies that discussed mobile apps and mobile banking. In general, these studies focused on the user's end of mobile apps with respect to needs, expectations, ratings, reviews, and consequences such as sales and brand loyalty. We intended to show a gap in literature because it lacked the bank's perspective. We expand on making this case in the next section.

\section{Research Question and Hypotheses}

Like many other industries, banking has adopted mobile banking ( $\mathrm{m}$-banking). In the context of this research project, we confine m-banking to the use of a bank's mobile app to complete customer transactions. As mobile technology evolves, banks have ventured into the new frontier like other industries. In a qualitative study about mobile payment adoption, Mallat [40] found out that the study participants considered banks as one of the trustworthy and reliable mobile services provider and mobile users preferred them to lesser known entities. As banks have added Internet services, the introduction of smartphones in the last decade has opened consumer's eyes to better technology products
[57], and possibly, higher expectations and demands from business services. For this study, we are interested in assessing banking mobile app maturity with respect to advances in mobile development. We sought the ratings of these apps to answer the research question: Are the banking industry's mobile app ratings indicators of meeting consumer needs?

Mobile technologies afforded financial institutions and other businesses new markets to offer their products [56]. Goh and Kauffman [16] conducted a study on strategy with respect to Internet banking. The study found that there was correlation between investment in technology and strong performance. Such investments influence strategic organizational implications [40]. The growth in Internet markets started to dictate new business models and relationships between a bank and its customers.

A combination of user's needs and expectations affect product rating and reviews [14]. It is safe to suggest that a user will gravitate toward any product (ex. App) if he/she needs that product. For example, if a user is an adventurer who travels often, he/she will need an app for maps and driving directions. One can assume that this app will have the latest maps, routes, and traffic updates.

Hoehle and Venkatesh [18] discussed the importance of consumer needs to mobile products perceptions. They used Apple's User Experience Guidelines to develop a conceptual framework for mobile app usability. They defined mobile app usability as "...as the extent to which a mobile application can be used by specified users to achieve specified goals with effectiveness, efficiency, and satisfaction in a specified context of use." (p. 437). They emphasized the importance of the relevance of the mobile app content to the target user. They rationalized their recommendation with the idea that positive user experience generates brand loyalty, a long-term value proposition for the organization. A key component of usability is user-friendliness as mobile technology products are intuitive, easy to use, and present useful functionality (interface and features) [13].

\subsection{Mobile App Versions}

The App Store offers a star rating system for the current version and an average for all versions. Such ratings form a data source that relays users' perceptions). These documented perceptions are helpful in assessing the evolvement of these apps. These are helpful to the developers who can address negative perceptions by improving the app in new versions [26]). Though the App Store's documents present guidelines about software versioning, the store cannot force such guidelines [26]. Because of that, developers are not required to provide much information about their new updates [43]. 
Lee and Raghu [30] discussed mobile app versioning within the context of finding determinants of mobile apps' success. They presented the change in a mobile app version as a "quality update" (p. 17). They explained that information about an update or updates would be shared by the developers in the app Description area. Hsu and Lin [19] also looked at mobile apps versioning in a study about paid mobile apps purchasing intentions. They reasoned that a free version of an app posed a threat to a paid version of the same app, even though the paid version would include more, and possibly better, features.

In general, mobile apps tend to be easier and faster to update in new versions than traditional software applications. The various versions of iPhone mobile apps sometimes can be up to three or four-digit form (example, 3.7.3.1). Users have significant inclination for frequently updated apps because they consider that the developer of that app continuously seek to improve it [43], [30]. Consequently, a newer version of a mobile app is assumingly better than the previous version. Thus, we posit that:

H1: Mobile banking apps will have better user ratings as they progress in the future.

\subsection{Mobile App Features}

User ratings focus on the attributes or features of the product or service. This review studies that considered whether software products with more features were more desirable to the consumer. Studies that considered the possible advantages and disadvantages of mobile apps containing more features include Khalid, Shihab, Nagappan, and Hassan (2015); Mendiola, Kalnicki, and Lindenauer, (2015); Tian, Nagappan, Lo, and Hassan (2015).

Tian et al (2015) used eight dimensions (examples included size of app and complexity of code) to study how high-rated apps are different from low-rated apps. They found out that the size of an app was one of most influential factors. They rationalized that high-rated apps tended to have a larger number of features than the low-rated apps. Gebauer et al. (2008) had presented a study that related product ratings to user requirements. The research project used content analysis of online ratings of mobile devices and presented four constructs (functionality, portability, performance, and usability) that considerably influence user ratings and reviews. Khalid et al. [26] conducted a study on mobile app development based on their premise that mobile app developers produce free apps to attract users and gain good reputation hoping that they could sell more advanced versions for profit. One specific finding was that users complained about the hidden cost, and thus, low ratings of such apps. Another major finding was recognizing the importance of software maintenance for mobile apps. They believed that their study could help developers quality assurance practices by identifying features use like or hate.

Mendiola et al. [4], also, found mixed evidence for the value of having more app features. Their study investigated the relationship between 12 common mobile health app features and user ratings. Out of 12 common features, only five had a positive and statistically significant relationship to user ratings (orders, export of data, cost information, and usability), while one feature had a negative, significant effect on ratings (a tracker feature). Users appreciated simplicity, intuitiveness, and time-saving features. The study downplayed the importance of the number of features, concluding that seven of the most common features had no significant relationship to user ratings and one was even negative.

In the same context, Iacob and Harrison's (2013) study presented a prototype for mining ratings of mobile apps for number of feature requests. They reasoned that the design of the prototype was initiated by the ways users expressed feature requests in their reviews. The study used a sample of 161 highly rated apps (average rating 4.27 out of 5) and found that “...Apps rated higher get far more feature requests than apps rated lower... more that $70 \%$ of the apps rated higher than 3 were associated with at least one feature request..." (p. 42). Naturally, a user may have mixed feelings about these features, some positive and some negative [61]. If all of the features a mobile app offers are perceived as useful, the user will have a positive impression of that app. Given these insights, we posit that:

H2: The number of features in a mobile banking app will be positively related to better ratings.

\subsection{Number of Ratings as an Indicator of Product Quality or Success}

Potential customers (or buyers) of a service or a product look at existing ratings and reviews to decide whether they you will pursue a product or a service [10], [12]. Banks, as providers of financial products and services, get ratings and reviews of their mobile apps. Certainly, a larger bank with millions of customers is likely to have more users of its mobile banking app. These organizations, by updating their product and services, can satisfy their current customers and open the doors for new ones [36]). Therefore, potential customers find comfort in finding such information that discusses the product, its features, its utility, and other important aspects.

Zhang, Ye, Law, and Li (2010) investigated the impact of e-word-of-the-mouth on consumer purchases. One observation they offered was that having a large number of reviews would help push consumers to see that product as viable purchase. In 
essence, more is better. Thus, consumers are encouraged by the existence of many others who have already purchased the same product. The large number of reviews would add credibility to the product's value. These reviews also positively contribute to the value of the rating, and more importantly, a favorable perception of said product.

Palomba et al. (2015) investigated how user reviews of mobile apps can help app developers improve their products, and further, how the improvements reflect on follow-up user reviews. The study relied on three research questions one of which (RQ) investigated the effect of crowd reviews. The found that "...apps implementing a higher number of ratings always exhibit a statistically significantly higher increment of their average score than apps having a lower percentage of reviews implemented..." (p. 298). They believed that the more informative the user reviews the better the new version of the app. higher the percentage of useful user reviews. Thus, we posit that:

H3: The number of existing ratings of a mobile banking app will be related to better ratings.

\subsection{Mobile App File Size}

In software engineering research, it is well known that functionality is correlated with software filesize [46]. While users typically want more features, a software package or application's file size can become problematic when transmitting it - whether over the Internet or through the airwaves, as in the case of mobile apps. User satisfaction is known to decline when system response time becomes even a few seconds slower [52]. Thus, understanding the pros and cons of having larger app file sizes may be an important driver of mobile user satisfaction. For example, Boiano, Bowen, and Gaia [5] discussed file size in their research on the processes involved in creating and distributing iPhone apps. They shed light on the importance of concise file size to help speed the download process for an app. As they described, app file size become large with the use of graphics, animations, and audio components. This matter pushed Apple to enact a policy that an app whose size was larger than 20 megabytes would need a wireless connect not to inflict on network resources. Ghose and Han [15] attributed that several app characteristics form the basis for users' preferences, and thus, the content of their reviews. For example, they noted that user reviewers mentioned app file size, app version, app age (days since app release), and app version age (days between different version releases).

Kendall, Nino, and Stewart [24] suggested that file size affects performance at two different levels: the speed by which in downloading and installing a software application and they indicate the increase in number of features. Similarly, there exists research
[30] that correlates app properties such as file size and detailed description to app sales. In another study, Ghose and Han [15] investigated the drivers for consumer demand in mobile apps. One of their findings suggested that larger file sizes could hinder potential users' demand for apps. Specifically, they observed that a $10 \%$ increase in app file size reduced user demand by $1.1 \%$. This underscored the downside of larger app sizes, especially if app success is evaluated based on the number of user downloads of the app. While Ghose and Han analyzed file size and the number of features, in terms of their impact on user demand and development cost, our current study will look at file size and features in with respect to user reviews.

Liu, Au, and Choi [38] discussed mobile app file size in their empirical study of mobile app offerings. They used it as one of the variables in a model that explored the effect of the freemium strategy for mobile apps. The study found that "...freemium strategy is positively associated with increased sales volume..." (p. 1). That, in turn, indicated that the reviews of free version on an app can help improve the paid version. Similarly, McIlroy et al. [43] used one of their projects to investigate mobile app update frequency from a software development perspective. They used over 10,000 apps to answer three questions: "...How frequently and consistently are apps updated... What is the rationale for frequent updates... What is actually changing for frequent updates?" (p. 1347). The answer for this last question provided some insight in mobile apps file size. First, in general, mobile app updates (code change) resulted in an increase in file size $(6 \%)$. Second, and more importantly, the study found out that mobile app updates were received positively. The authors observed that frequently updated apps have earned better user ratings. Thus, we posit that:

H4: The file size of a mobile banking app will be related to better ratings.

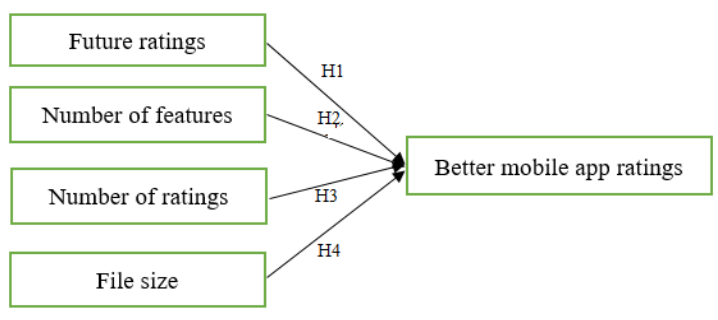

Figure 1. Research model

\section{Methodology}

We consulted a list of the top 50 largest banks registered with the U.S. Federal Deposit Insurance Corp. (FDIC), a U.S. federal agency whose mission is 
to ensure stability and earn public confidence in the U.S. banking system. We then searched the Apple iTunes website to identify the existence of a corresponding app for each bank. Thus, the sample $n$ for the three years included $2012(n=39), 2016(n=41)$ and $2018(\mathrm{n}=46)$. The data was collected in years with variation durations: four years between 2012 and 2016 and two years between 2016 and 2018. We thought the number of banks with mobile apps would increase continuously, and therefore, a bigger number of ratings. The sample $(n)$ difference in the data meant that ratings did not exist for some of these banks in these years. For example, Bank of America's app had ratings for all three years, but Goldman Sachs' app only had data for two of the three periods (2016 and 2018); there was no mobile app for Sachs in 2012. The assuring thing for this sample was that this study was consistent with using the top 50 richest banks regardless.

We copied details of the ratings and features of each bank's app to an Excel spreadsheet. We recorded following data for each app for the three years: (a) app version number; (b) app size (in megabytes); (c) number of customer ratings for the latest version; (d) number of ratings per each star rating (number of ratings providing one star, two stars, etc.); and (f) the number of features documented by iTunes). With regards to the number of features, we identified this value based on reading the short descriptions provided on the iTunes site for the current app version as well as for previous versions (see Figure 2). We counted the number of features by treating each description of a new capability as a separate feature. We did not count anything related to bug fixes as new feature (see, for example, versions 7.4.12 and 7.4.8 in the Figure, below). We summed the number of features based on the current and prior app versions displayed on the iTunes site.

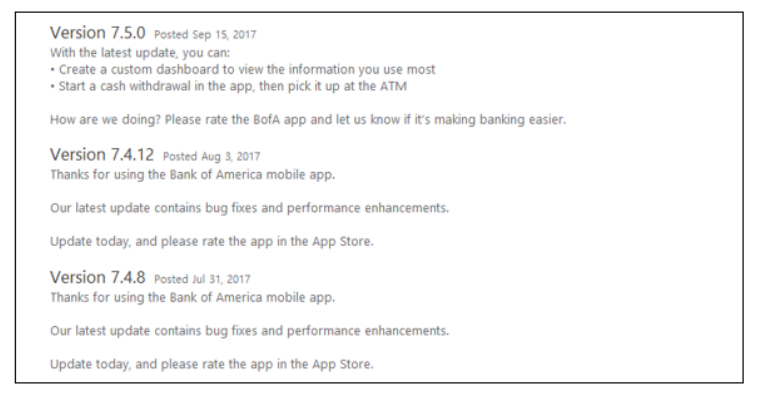

\section{Figure 2. Banking app version update sample}

Apple iTunes uses a five-star rating scale with customers choosing "1 star" to designate "I hate it" up to "5 stars" to designate "it's great." A three-star rating is considered a moderate view - also known as the "middle-ground attitude" [48]. While the star ratings for mobile banking apps vary from one to five, the mean is typically high and the extreme ratings of
"1" and " 5 " typically account for a majority of the scores [21]. We used the 5:1 ratio as support for our data analysis.

\section{Analysis and Results}

We first processed and cleaned the data using Excel to compute descriptive statistics for all constructs. We started by weighing number of customer ratings and star ratings, the mean rating was 3.36 in 2012, 4.52 in 2016 and 4.82 in 2018. In contrast, unweighted means (averaging the means for all banks, despite the number of ratings) was 3.23 in 2012, 3.12 in 2016 and 3.9 in 2018. These differences suggested that the most frequently reviewed bank apps had much higher customer ratings. Additionally, we conducted an overall comparison for the ratings of 2012, 2016 and 2018. They showed the similar behavior and observed J-shape plot where there was higher percentage of people rating 1 and 5 as compared to 2, 3 and 4 . The rating 5 being the highest and 1 being the lowest. In addition, a simple analysis of the extremes provided in Table 1.

Table 1. Comparison of 1-star and 5-star ratings for three years

\begin{tabular}{l|c|c|c|c|c}
\hline Yr & $\begin{array}{l}\text { Total no. } \\
\text { of ratings }\end{array}$ & $\begin{array}{l}\text { No. of } \\
\underline{\mathbf{1 - s t a r}} \\
\text { ratings }\end{array}$ & $\begin{array}{l}\text { \% of } \\
\frac{\text { 1-star }}{\text { \% }}\end{array}$ & $\begin{array}{l}\text { No. of } \\
\frac{\text { 5-star }}{\text { ratings }}\end{array}$ & $\begin{array}{l}\text { \% of } \\
\frac{\text { 5-star }}{\text { \% }}\end{array}$ \\
\hline 2012 & 7,273 & 2009 & $28 \%$ & 3,106 & $42.71 \%$ \\
\hline 2016 & 30,365 & 1744 & $6 \%$ & 23,142 & $76.21 \%$ \\
\hline 2018 & $4,710,106$ & 46,187 & $1 \%$ & $4,120,931$ & $87.49 \%$ \\
\hline
\end{tabular}

The J-shaped ratings plot in Figure 3 was asymmetrical i.e. the frequencies are higher on the extremes as compared to the frequencies of other ratings. The ratings is $\mathrm{J}$-shaped distribution where the frequencies are higher on the extremes as compared to the frequencies of other ratings. The rating 5 being the highest number and 1 being the second highest number. Hu et al. [20] mentioned that the people who either moan or brag are more likely to express their views. Khalid et al. [26] echoed the same sentiment. Hence, resulting in the more people rating at the extremes (5-star or 1-star) than those with moderate views leading to J-distribution. 


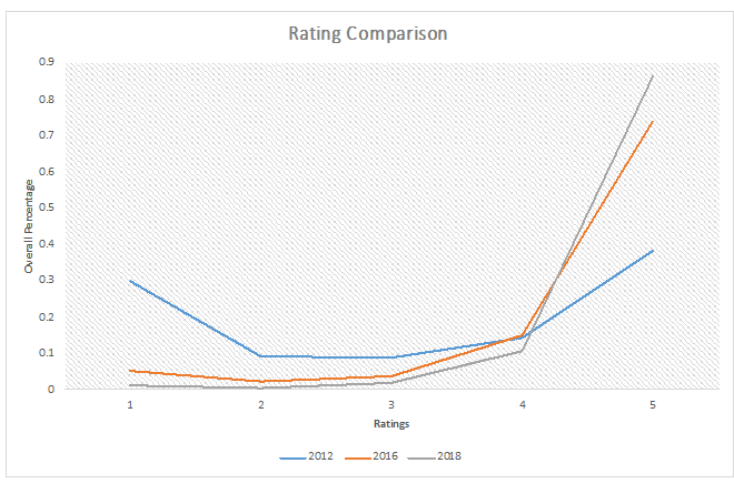

Figure 3. Ratings comparison for 2012, 2016, and 2018

The non-parametric distribution that called for an approach that did not rely on any of the parameters but the ranking or the ordered data (Kerby, 2014). These are often called as distribution free approach and is based on fewer assumptions. Wilcoxon (1945) suggested when the data is collected at different time points and within pair differences are ordinal that needs non-parametric approach.

The nature of the sample called for the use of Generalized Estimating Equations (GEE) for analysis. Liang and Zeger [33] introduced GEE to treat clustertype data. Because the group designation (top 50 riches banks) was more important than the individual banks, GEE was a worthy choice. We noted at the beginning of this section that some data was present for all three periods for most banks, but was missing for some, GEE was recommended to overcome the discrepancies [17].

McGrath et al. [42] found that in their study of physicians' online ratings that most of the ratings are at the extremes, with most rated at 1 or 5 and recommended. They relied on using the 5 to 1 ratio based on previous work in psychology. Also, Huber et al. [22] analyzed the online content of urogynecologists' ratings to transform ratings to improve care. They compared 5:1 ratio with various characteristics and practice qualities to assess physicians' performance. This current study has similar 5 to 1 ratio undertones as Table 2 shows. Thus, we used the same principle of 5:1 ratio as basis for testing our hypotheses.

The simple Linear Regression Model with GEE was performed - the 5:1 ratio is regressed against the categorical variable year. From the Results 1, the year 2016 is found significant when considering the pvalue of the Wald Statistic of 0.0402 (less than 0.05) and 2018 years are found most significant when considering the p-value of the Wald Statistic of 0.000087 (less than 0.05). The year 2016 and year 2018 being significant supports that the ratings improved from 2012 to 2016, and ratings further improved from 2016 to 2018. This supports Hl:
Mobile banking apps will have better user ratings in as they progress in the future.

Table 2. H1 result summary

\begin{tabular}{|c|c|c|c|c|c|}
\hline DV & IV & Result & $\begin{array}{l}\text { Test } \\
\text { Used }\end{array}$ & $\begin{array}{l}\text { Stat } \\
\text { Used }\end{array}$ & $\begin{array}{l}\text { p- } \\
\text { value }\end{array}$ \\
\hline \multirow[t]{2}{*}{$\begin{array}{l}5: 1 \\
\text { Ratio }\end{array}$} & $\begin{array}{l}\text { Year } \\
2016\end{array}$ & Sig. & \multirow{2}{*}{$\begin{array}{l}\text { Linear } \\
\text { Regression } \\
\text { Model with } \\
\text { Generalized } \\
\text { Estimating } \\
\text { Equations }\end{array}$} & \multirow[t]{2}{*}{$\begin{array}{l}\text { Wald } \\
\text { Statistic }\end{array}$} & 0.040 \\
\hline & $\begin{array}{l}\text { Year } \\
2018\end{array}$ & $\begin{array}{l}\text { Most } \\
\text { Sig. }\end{array}$ & & & $<0.001$ \\
\hline
\end{tabular}

To address the relationship within the sample of each year or among the data for the three years, we used the Wald test. It is a parametric statistical test to express relationship within a sample or among data items as a linear model. A main feature for this test is that it is more effective at joint group comparison test than many other ratio tests [34]. It can help find out whether input variables in the model can explain the model or not, or if they are significant or not. If the probability of Wald Statistic was less than or equal to (1- $\alpha$ ) where $\alpha$ was equal to $95 \%$ confidence interval, then the variable was significant. The data was first categorized based on the banks and year as the subcategory. We then tested the data for the various hypotheses.

Two tests were performed with GEE. Initially, the 5:1 ratio was regressed against the mobile app size variable. Secondly, the 5:1 ratio was regressed against the mobile app size and year. Then, the F-test from ANOVA was used to compare the two above models in order to find if the file size played a significant role in improving predicting the ratings over the years.

The simple regression model with 5:1 ratio as dependent variable and size as the independent variable. As shown in the Results 2, the slope was non-zero with value of 0.1673 and was significant when considering the $\mathrm{p}$-value of the Wald Statistic of 0.006 . That indicated that size was significantly associated with the ratio. The hypothesis could not be rejected that the file size of the mobile app was related to better ratings.

The second regression result for the model as shown in Result 3 - 5:1 ratio as output variable and Size and Year as the input variables. The slope of Size with the value of 0.1278 was marginally significant considering the p-value of the Wald Statistic of 0.067 (greater than 0.05). The impact of Year 2016 and 2018 was captured by the slope values -3.5655 and 15.8622 . Considering the p-values of the Wald Statistic into account - it seemed that there was no significant impact for the Year 2016 (p-value: 0.513>0.05) but there was significant impact for Year2018 (p-value: $0.044<0.05)$. 
Table 4. H3 result summary

Table 3. $\mathrm{H} 2$ result summary

\begin{tabular}{|c|c|c|c|c|c|}
\hline DV & IV & Result & $\begin{array}{l}\text { Test } \\
\text { Used }\end{array}$ & $\begin{array}{l}\text { Stat } \\
\text { Used }\end{array}$ & $\begin{array}{l}\mathrm{p}- \\
\text { value }\end{array}$ \\
\hline $\begin{array}{l}5: 1 \\
\text { Ratio }\end{array}$ & Size & Sig. & $\begin{array}{l}\text { Linear } \\
\text { Regression } \\
\text { Model with } \\
\text { Generalized } \\
\text { Estimating } \\
\text { Equations } \\
\end{array}$ & $\begin{array}{l}\text { p-value } \\
\text { of Wald } \\
\text { Statistic }\end{array}$ & 0.006 \\
\hline \multirow{3}{*}{$\begin{array}{l}5: 1 \\
\text { Ratio }\end{array}$} & Size & Marg. Sig. & \multirow{3}{*}{$\begin{array}{l}\text { Linear } \\
\text { Regression } \\
\text { Model with } \\
\text { Generalized } \\
\text { Estimating } \\
\text { Equations }\end{array}$} & \multirow{3}{*}{$\begin{array}{l}\text { p-value } \\
\text { of Wald } \\
\text { Stat }\end{array}$} & 0.067 \\
\hline & $\begin{array}{l}\text { Year } \\
2016\end{array}$ & Insig. & & & 0.513 \\
\hline & $\begin{array}{l}\text { Year } \\
2018\end{array}$ & Sig. & & & 0.044 \\
\hline
\end{tabular}

However, size was significant in the first model but was not in the second model. The Year2018 was making significant impact whereas Year2016 was not. That implied that Year itself was not significant. Two more tests were performed with GEE. Initially, the 5:1 ratio was regressed against the number of features in the mobile applications. Secondly, the 5:1 ratio was regressed against the number of features and the year. Finally, the F-test from ANOVA test was used to compare the two above models.

The first regression result for the model - 5:1 ratio as output variable and number of features as the input variable. As shown in the Results 4, the slope was non-zero with value of 1.669 and was marginally significant when considering the $\mathrm{p}$-value of the Wald Statistic of 0.056 (less than 0.05) indicates that size was significantly associated with the ratio. The null hypothesis can be rejected indicating that there was significant relationship between the file size of the mobile app and the 5:1 ratio. The hypothesis confirms that the number of features of the mobile app was related to better ratings.

The second regression result for the model- 5:1 ratio as output variable and number of features and Year as the input variables. As shown in the Results 5, the slope of Features with the value of 1.276 was not significant considering the p-value of the Wald Statistic of 0.1865 (greater than 0.05). The impact of Year 2016 and 2018 was captured by the slope values -4.615 and 23.81. Considering the p-values of the Wald Statistic into account - it seems that there was no significant impact for the Year 2016 (p-value: $0.5182>0.05)$ but there was significant impact for Year2018 (p-value: $0.0024<0.05$ ). The statistical results showed that number of features was not significant, and Year was not significant either.

\begin{tabular}{l|l|l|l|l|l}
\hline DV & IV & Result & $\begin{array}{l}\text { Test } \\
\text { Used }\end{array}$ & $\begin{array}{l}\text { Stat } \\
\text { Used }\end{array}$ & $\begin{array}{l}\text { p- } \\
\text { value }\end{array}$ \\
\hline $\begin{array}{l}\text { 5:1 } \\
\text { Ratio }\end{array}$ & Features & $\begin{array}{l}\text { Marg. } \\
\text { Sig }\end{array}$ & $\begin{array}{l}\text { Linear } \\
\text { Regression } \\
\text { Model with } \\
\text { Generalized } \\
\text { Estimating } \\
\text { Equations }\end{array}$ & $\begin{array}{c}\text { p-value } \\
\text { of } \\
\text { Wald } \\
\text { Statistic }\end{array}$ & 0.056 \\
\hline 5:1 & Features & Insig. & $\begin{array}{l}\text { Linear } \\
\text { Regression } \\
\text { Model with } \\
\text { Generalized } \\
\text { Estimating } \\
\text { Equations }\end{array}$ & $\begin{array}{l}\text { p-value } \\
\text { of Wald } \\
\text { Statistic }\end{array}$ & 0.186 \\
& & & & \\
\hline
\end{tabular}

Finally, the features variable was marginally significant in the first model but was not in the second model. The Year2018 was making significant impact whereas Year2016 was not implied that Year itself did not play any significant role. As a result, the test failed to support the relation between the number of features and ratings.

The same approach was used for $H 4$. The 5:1 ratio was regressed against the number of ratings (ratings count). The ratings count was found significant when considering the p-value of the Wald Statistic of 0.00014 (less than 0.05). The ratings count being significant supports the ratings improved with the increase in the count of ratings. Thus, we could not reject H4: The increase in number of ratings showed improvements in app ratings.

Table 5. H4 result summary

\begin{tabular}{l|l|l|l|l|l}
\hline DV & IV & Result & $\begin{array}{l}\text { Test } \\
\text { Used }\end{array}$ & $\begin{array}{l}\text { Stat } \\
\text { Used }\end{array}$ & p-value \\
\hline $\begin{array}{l}\text { 5:1 } \\
\text { Ratio }\end{array}$ & $\begin{array}{l}\text { No. of } \\
\text { Ratings }\end{array}$ & Sig. & $\begin{array}{l}\text { Linear } \\
\text { Reg. } \\
\text { Model } \\
\text { with } \\
\text { GEE }\end{array}$ & $\begin{array}{l}\text { p-value } \\
\text { of Wald } \\
\text { Stat }\end{array}$ & \\
\hline
\end{tabular}

The mobile banking ratings not only improved over time (HI) but the number of reviewers also - this was evident from the increase in the number of ratings count (H4). The increase in either number of features $(H 2)$ and file size $(H 3)$ or are not playing significant role in improving the 5:1 ratings ratio. This study calls for further investigation into the rationale of adding more features, which usually causes the increase in the file size. 
Table 6. All hypotheses result summary

\begin{tabular}{l|l}
\hline Hypothesis & Result \\
\hline $\begin{array}{l}\text { H1: Mobile banking apps will have better } \\
\text { user ratings in as they progress in the } \\
\text { future }\end{array}$ & Supported \\
\hline $\begin{array}{l}\text { H2: The number of features in a mobile } \\
\text { app will be positively related to better } \\
\text { ratings. }\end{array}$ & Not Supported \\
\hline $\begin{array}{l}\text { H3: The number of existing ratings of a } \\
\text { mobile app will be related to better } \\
\text { ratings. }\end{array}$ & Supported \\
\hline $\begin{array}{l}\text { H4: The file size of a mobile app will be } \\
\text { related to better ratings. }\end{array}$ & Not Supported \\
\hline
\end{tabular}

\section{Limitations and Delimitations}

This had some limitations and a delimitation. First, while we collected data for three time points (the years 2012, 2016 and 2018), iTunes does not store historical data, we were unable to capture the customer ratings data during the intermediate years (2013, 2014, 2015 or 2017). A second limitation was that iTunes provided customer ratings only for the current app version during the current year. This meant that if a given bank produced multiple app versions during a given year, only the customer ratings for the most current version were available and not earlier versions.

As a delimitation, the study was confined to data from the iPhone platform (iOS) apps and App Store for experiment controls purposes. It is acceptable to focus on single-platform apps in empirical research on mobile apps (Fu et al., 2013).

\section{Conclusion, Implications, and Future Research}

This research project is an empirical study on banking mobile apps. It aimed to add to the limited research of the business' perspective of mobile app development. The data for the analysis were collected for three years. The analysis was based on quantitative metrics (app star ratings) that were available on the App Store website for three periods (2012, 2016 and 2018). The study included information on the nature of sample and its unbalanced nature.

Also, the use of the $5: 1$ ratio measure is a noteworthy contribution of this study. Hu et al. [20] explained that the 5:1 ratio could be interpreted as how many people disliked as compared to number of people liked something. Using 5:1 ratio metric minimizes the data skewness without losing the context of the useful information for the analysis. Levy, Duan, and Boo [32] emphasized the importance of one-star reviews. Their study favored that businesses should use these specific ratings as a gauge for performance.

Second, this study looked at a small sample from the banking industry. The study found that there were significant improvements in banking mobile apps star ratings between 2012 and 2018. Mobile apps are daily bread for many industries [11]. The study did not consider other factors but the ratings, investigation of the literature did not produce any information on the relationship between mobile development and strategic planning.

One research possibility is to do a similar study for consecutive years instead of having that time gap. It is also possible for future studies to analyze customers' qualitative comments as well [48]. Another research possibility is to compare the ratings of mobile apps in different industries. One major control to consider is the number of revisions of each version of the respective apps. As noted previously, there is expansive literature that analyzes customers' qualitative comments (reviews), in contrast to customers' numeric ratings of products and services (ratings). Given that qualitative ratings contain different information, and at times, the same customer's review contradicts their own ratings, there are many lines of future research possibilities in customer ratings. More research is needed on the use of reviews and ratings into development decisionmaking in the banking industry. This research could investigate into the weight of mobile app development with respect to strategic planning in banking.

\section{References}

[1] Ali, M., Joorabchi, M., and Mesbah, "A. Same App, Different App Stores: A Comparative Study.“ Proceedings of the $4^{\text {th }}$ ACM International Conference on Mobile Software Engineering and Systems, pp. 7990.

[2] Archak N., Ghose A., and Ipeirotis P. (2008). "Deriving the pricing power of product features by mining consumer reviews." Working paper, New York University, New York

[3] Ballinger, G. A. (2004). "Using Generalized Estimating Equations for longitudinal data analysis." Organizational Research Methods, 7(2), pp. 127-150.

[4] Basole, R. C., Karla, J. (2012). "Value Transformation in the Mobile Service Ecosystem: A Study of App Store Emergence and Growth." Service Science, 4(1), pp. 24-41.

[5] Boiano, S., Bowen, J., and Gaia, G. (2012). "Usability, design and content issues of mobile apps for cultural heritage promotion: The Malta culture guide experience." Electronic Visualisation and the Arts.

[6] Ruxton, G. D. (2006). "The unequal variance t-test is an underused alternative to student's t-test and the Mann-Whitney U test." Behavioral Ecology, 17(4), pp. 688-690.

[7] Byers, R. E., Lederer, P. J. (2015). "Retail bank services strategy: A Model of traditional, electronic, 
and mixed distribution choices." Journal of Management Information Systems, 18(2), pp. 133-15.

[8] Dauda, Y., and Lee, J. (2015). "Technology adoption: A conjoint analysis of consumers' preference on future online banking services." Information Systems, 53, pp. $1-15$.

[9] Deloitte (2010). "Mobile banking a catalyst for improving bank performance." Deloitte Development LLC. New York, NY.

[10] Duan, W., Gu, B., and Whinston, A. B. (2008). "The Dynamics of online word-of-mouth and product sales: An empirical investigation of the movie industry." Journal of Retailing, 84(2), pp. 233-242.

[11] Flora, H., Wang, X., and Chande, S. (2014). "An investigation on the characteristics of mobile applications: A survey study." I. J. Information Technology and Computer Science, 11, pp. 21-27.

[12] Forman, C., Ghose, A., and Wiesenfeld, B. (2008). "Examining the Relationship between Reviews and Sales: The Role of Reviewer Identity Disclosure in Electronic Markets." Information Systems Research, 19, pp. 291-313.

[13] Forrester Research (2011). "Mobile app design best practices". Forrester Research, Inc. Cambridge, MA.

[14] Gebauer, J., Tang, Y., and Baimai, C. (2008). "User requirements of mobile technology: results from a content analysis of user reviews." Information Systems and e-Business Management 6 (4), pp. 361-384.

[15] Ghose, A., and Han, S. P. (2014). "Estimating demand for mobile applications in the new economy." Management Science, 60 (6), pp. 1470-1488.

[16] Goh, K. H., and Kauffman, R. J. (2013). "Firm strategy and the Internet in US commercial banking." Journal of Management Information Systems 30 (2), pp. 9-40

[17] Halekoh, U., Højsgaard, S., Yan, J. (2006). "The R package geepack for Generalized Estimating." Journal of Statistical Software, 15(2), pp. 2-11.

[18] Hoehle, H., and Venkatesh, V. (2015). "Mobile application usability: conceptualization and instrument development.” MIS Quarterly, 39(2), pp. 435-472.

[19] Hsu, C., and Lin, J. C. (2015). "What drives purchase intention for paid mobile apps? - An expectation confirmation model with perceived value." Electronic Commerce Research and Applications, 14(1), pp. 4657.

[20] Hu, N., Bose, I., Koh, N. and Liu, L. (2012). "Manipulation of online reviews: An analysis of ratings, readability, and sentiments." Decision Support Systems, 52, pp. 674-684

[21] Hu, N., Pavlou, P. A., and Zhang, J. (2009) "Overcoming the J-Shaped Distribution of Product Reviews." Communications of the ACM, 52(10), pp. 144-147.

[22] Huber, S., Kasabwala, K., Priestley, J. L., Gadidov, B., and Culligan, P. J. (2018). "Understanding your online ratings: a methodological analysis using urogynecologists in the United States.” Female Pelvic Medicine and Reconstructive Surgery.

[23] Jeong, H. and Koo, D. (2015). "Combined effects of valence and attributes of e-WOM on consumer judgment for message and product.” Internet Research, 25(1), pp. 2-29.

[24] Kendall,S. L., Nino, M., and Stewart, S. (2010). "Using the iPhone and iPod touch @Work." Computers in Libraries, pp. 14-19.
[25] Ketelaar, P.E., Willemsen, L. M., Sleven, L. and Kerkhof, P. (2015). "The good, the bad, and the expert: how consumer expertise affects reviews valence effects on purchase intentions in online product reviews." Journal of Computer-Mediated Communication, 20(6), pp. 649-666.

[26] Khalid, M., Asif, M., and Shehzaib, U. (2015). "Towards improving the quality of mobile app reviews." International Journal of Information Technology and Computer Science (IJITCS), 7(10), pp. 35-41.

[27] Kim, C., Mirusmonov, M., and Lee, I (2010). “An empirical examination of factors influencing the intention to use mobile payment." Computers in Human Behaviour, 26(3), pp. 310-322.

[28] Kim, G., Shin, B., and Lee, H. G. (2009). "Understanding dynamics between initial trust and usage intentions of mobile banking." Information Systems Journal, 19(3), pp. 283-311.

[29] Larivière, B., Joosten, H., Malthouse, E. C., van Birgelen, M., Aksoy, P., Kunz, W. H., and Huang, M. H. (2013). "Value fusion: The blending of consumer and firm value in the distinct context of mobile technologies and social media." Journal of Service Management, 24(3), pp. 268-293.

[30] Lee, G., and Raghu, T. S. (2014). "Determinants of Mobile Apps' Success: Evidence from the App Store Market." Journal of Management Information Systems, 31(2), pp. 133-169.

[31] Lee, J., Park, D., and Han, I. (2011). "The different effects of online consumer reviews on consumers' purchase intentions depending on trust in online shopping malls: An advertising perspective." Internet Research, 21(2), pp. 187-206.

[32] Levy, S. E., Duan, W., and Boo, S. (2013). "An Analysis of One-Star Online Reviews and Responses in the Washington, D.C., Lodging Market." Cornell Hospitality Quarterly, 54(1), pp. 49-63.

[33] Liang, K., \& Zeger, S. L. (1986). "Longitudinal data analysis using Generalized Linear Models." Biometrika, 73(1), pp. 13-22.

[34] Liao, T. F. (2004). "Comparing social groups: Wald statistics for testing equality among multiple logit models." International Journal of Comparative Sociology, 45(1), pp. 3-16.

[35] Lin, C. A., and Xu, X. (2017). "Effectiveness of online consumer reviews: The influence of valence, reviewer ethnicity, social distance and source trustworthiness." Internet Research, 27(2), pp. 362-380.

[36] Lin, H. (2011). "An empirical investigation of mobile banking adoption: The effect of innovation attributes and knowledge-based trust." International Journal of Information Management, 31(3), pp. 252-260

[37] Lin, J., Wang, B., Wang, N., and Lu, Y. (2011). "Understanding the evolution of consumer trust in mobile commerce: a longitudinal study." Information Technology and Management, 15 (1), pp. 37-49.

[38] Liu, C. Z., Au, Y. A., and Choi, H. S. (2014). "Effects of Freemium Strategy in the Mobile App Market: An Empirical Study of Google Play." Journal of Management Information Systems, 31(3), pp. 326-354.

[39] Lumley T, Diehr P, Emerson S, Chen L (2002). "The importance of the normality assumption in large public health data sets." Annual Review of Public Health 23, pp. 151-169. 
[40] Mallat, N. (2007). "Exploring consumer adoption of mobile payments - A qualitative study." Journal of Strategic Information Systems, 16(4), pp. 413-432

[41] Martins, C., Oliveira, T., and Popovič, A. (2014). "Understanding the Internet banking adoption: A unified theory of acceptance and use of technology and perceived risk application." International Journal of Information Management, 34(1), pp. 1-13.

[42] Mcgrath, R. J., Priestley, J. L., Zhou, Y., and Culligan, P. J. (2018). "The Validity of Online Patient Ratings of Physicians: Analysis of Physician Peer Reviews and Patient Ratings." Interactive Journal of Medical Research, 7(1).

[43] McIlroy, S., Ali, N. and Hassan, "Fresh apps: an empirical study of frequently-updated mobile apps in the Google play store." Empirical Software Engineering. 21(3), pp. 1346-1370.

[44] Mendiola, M. F., Kalnicki, K. and Lindenauer, S. (2015). "Valuable features in mobile health apps for patients and consumers: content analysis of apps and user ratings." JMIR mHealth and uHealth 3(2).

[45] Middleton. C., Scheepers, R., and Tuunainen, V. K. (2014). "When Mobile is the Norm: Researching Mobile Information Systems and Mobility as PostAdoption Phenomena." European Journal of Information Systems. 23(5), pp. 503-512.

[46] Minkiewicz, A. F. (2009). "The evolution of software size: A search for value." Software Engineering Technology, pp. 23-26.

[47] Montazemi, A. R., and Qahri-Saremi, H. (2015). "Factors Affecting Online Banking: A Meta-Analytic Structural Equation Modeling Study." Information and Management, 5(2), pp. 210-226.

[48] Mudambi, S.M. and Schuff, D. (2010) "What Makes a Helpful Review? A Study of Customer Reviews on Amazon.com.” MIS Quarterly, 34, pp. 185-200.

[49] Ngai, E. Gunasekaran, A. (2007). "A review for mobile commerce research and applications." Decision Support Systems, 43, pp. 3-15.

[50] Picoto, W.N., Bélanger, F., and Palma-dos-Reis, A. (2013). "M-business organizational benefits and value: a qualitative study." Journal of Organization Computing and Electronic Commerce, 23(4), pp. 287324.

[51] Preston, D. and Karahanna, E. 2009. "Antecedents of IS Strategic Alignment: A Nomological Network." Information Systems Research, 20(2), pp. 159-179.

[52] Rose, G. M., and Straub, D. W. (2001). "The effect of download time on consumer attitude toward the eservice retailer." E-service Journal, 1(1), pp. 55-76.

[53] Ruxton, G.D. (2006). "The unequal variance t-test is an underused alternative to Student's t-test and the MannWhitney U test.” Behavioral Ecology, 17(4), pp. 688690.

[54] Scornavacca, E., Barnes, S. J., and Huff, S. (2006). "Mobile Business Research, 2000-2004: Emergence, current status, and future opportunities." Communications of the Association for Information Systems, 17, pp. 635-646.

[55] Shah, M., Braganza, A., and Morabito, V. (2007). "A survey of critical success factors in e-Banking: An organisational perspective." European Journal of Information Systems, 16, pp. 511-524.

[56] Sheng, H., Nah, F. F. H., and Siau, K. (2005). "Strategic implications of mobile technology: A case study using value-focused thinking." Journal of Strategic Information Systems 14 (3), pp. 269-290.

[57] Sia, S. K., Soh, C., and Weill, P. (2016). "How DBS Bank Pursued a Digital Business Strategy." MIS Quarterly Executive, 15(2), pp. 105-121.

[58] Smith A., and Anderson M. (2016, Dec 19). "Online shopping and e-commerce: online reviews." Retrieved from http://www.pewinternet.org/2016/12/19/onlinereviews.

[59] Tallon, P. (2010). "A Service Science Perspective on Strategic Choice, IT, and Performance in U.S. Banking." Journal of Management Information Systems, 26(4), pp. 219-252.

[60] Tan, M., and Teo, T. S. (2000). "Factors influencing the adoption of Internet banking." Journal of the AIS, 1(5), pp. 1-42.

[61] Tang, C., Mehl, M. R., Eastlick, M. A., He, W., and Card, N. A. (2014). "A longitudinal exploration of the relations between electronic word-of-mouth indicators and firms' profitability: Findings from the banking industry." International Journal of Information Management, 36(6), pp. 1124-1132.

[62] Taylor, D. G., and Levin, M. (2014). "Predicting mobile app usage for purchasing and informationsharing." International Journal of Retail and Distribution Management, 42(8), pp. 759-774.

[63] Tian, Y., Nagappan, M., Lo, D., and Hassan, A. E. (2015). "What are the characteristics of high-rated apps? A case study on free Android applications." IEEE International Conference on Software Maintenance and Evolution (ICSME), Bremen, pp. 301-310.

[64] Troshani, I., and Rao Hill, S. (2007). "A proposed framework for mobile services adoption: A review of existing theories, extensions, and future research directions." Mobile Multimedia Communications: Concepts, Applications, and Challenges, pp. 85-108.

[65] Van Der Hijden, H. and Junglas, I. (2006). "Special Issue on mobile user behavior: Guest Editorial." European Journal of Information Systems, 14, pp. 249251. 